\title{
Effect of silver nanoparticle on the properties of poly(methyl methacrylate) nanocomposite network made by in situ photoiniferter-mediated photopolymerization
}

\author{
POOYAN MAKVANDI ${ }^{1}$, NASSER NIKFARJAM ${ }^{1,2, *}$, NASER SHARIFI SANJANI ${ }^{1}$ and \\ NADER TAHERI QAZVINI ${ }^{1,3}$ \\ ${ }^{1}$ Polymer Division, School of Chemistry, College of Science, University of Tehran, Tehran, Iran \\ ${ }^{2}$ Institute for Advanced Studies in Basic Sciences, Zanjan, Iran \\ ${ }^{3}$ Biomaterials Research Center (BRC), University of Tehran, Tehran, Iran
}

MS received 8 November 2014; accepted 26 May 2015

\begin{abstract}
Here we report preparation and characterization of poly(methyl methacrylate)/silver nanoparticles (PMMA/AgNPs) nanocomposite networks prepared via in situ photoiniferter-mediated photopolymerization (in situ PMP) using tetraethylthiuram disulphide (TED) as photoiniferter and 2,2-dimethoxy-2-phenylacetophenone (DMPA) as photoinitiator. Photopolymerization was performed in the presence of allyl methacrylate, as crosslinking agent, and various amount of silver nanoparticles (AgNPs). AgNPs were synthesized via chemical reduction of silver nitrate with $t$-BuONa-activated sodium hydride in tetrahydrofuran. The degree of monomer conversion (DC\%) during polymerization was followed quantitatively via Fourier transform infrared spectroscopy. DC\% of nanocomposite networks slightly increased with AgNPs content. Moreover, differential scanning calorimetry results disclosed a decrease in glass transition temperature $\left(T_{\mathrm{g}}\right)$ of the nanocomposite networks in comparison with the pure polymer network, suggesting the plasticizing effect of AgNPs. Swelling behaviour was also measured in water and ethanol/water $(3 / 1, \mathrm{v} / \mathrm{v})$ solution at $37 \pm 1^{\circ} \mathrm{C}$ after 30 days. The enhanced swelling ratio for nanocomposite networks with increase in the AgNPs content suggested the potential role of AgNPs in photo-crosslinking reactions. The flexural strength and modulus values resulted from three-point bending method revealed an improvement in mechanical properties of the nanocomposites in comparison with pure PMMA networks. The mechanical behaviour observations were rationalized based on the field emission scanning electron microscopy micrographs from the fractured surfaces of the nanocomposite networks. Finally, thermogravimetric analysis showed that while the AgNPs catalyse the degradation in the early stages, they subsequently act as a retardant agent against thermal degradation.
\end{abstract}

Keywords. PMMA network; silver nanoparticle; nanocomposite; in situ photoiniferter-mediated photopolymerization; swelling test.

\section{Introduction}

Poly(methyl methacrylate) (PMMA)-based resins are widely used in coating applications and dentistry. ${ }^{1-6}$ PMMA continues to be used because of its favourable working characteristics including processing ease, stability in oral environment, good colour stability, superior esthetics, usability with inexpensive equipments, good mechanical properties and wear resistance. ${ }^{7,8}$ However, microorganism growth on acrylic appliances limits their application in biological systems. ${ }^{9,10}$ An alternative approach to cope with this problem is utilization of antimicrobial nanoparticles to gain antimicrobial PMMA nanocomposites. Silver nanoparticles (AgNPs) are one of the most commonly used nanoparticles in this area, because of their antimicrobial activity as well as electrical conductivity and catalytic properties. ${ }^{9-13}$ The AgNPs have shown antimicrobial effects against many microorganisms such as E. coli, Staphylococcus eureus, Staphylococcus epidermidis,

\footnotetext{
*Author for correspondence (nikfarjam@iasbs.ac.ir)
}

Candida albicans and Streptococcus mutans ${ }^{11,14-16}$ and very low toxicity against human and animals. ${ }^{17,18}$

In medical appliance materials, in particular dental polymer materials, it is necessary for polymerization to be done with monomer conversion of $\sim 100 \%$ with trace residual monomer content. To gain this, an equilibrium between capped chains by deactivating agents and activated propagating chains, for maintaining a low radical concentration, is needed. This strategy is known as controlled radical polymerization, which includes atom transfer radical polymerization, reversible addition-fragmentation transfer polymerization, nitroxide-mediated polymerization and photoiniferter-mediated photopolymerization (PMP). Among them, PMP has attracted much attention due to utilizing of light for polymerization or curing for resins, which in turn leads to low cost, i.e., operating at room temperature and higher hardening speed of a solvent-free resin. ${ }^{19,20}$ There are several attempts to synthesis linear and brush PMMA by means of different photoiniferter, e.g., $N, N$-(diethylamino)dithiocarbamoylbenzyl (trimethoxy)silane (SBDC) $)^{21}$ and tetraethylthiuram disulphide 
(TED). ${ }^{22-26}$ Moreover, in another work brush and crosslinked hydrogel brushes were from polyacrylamide using SBDC as photoiniferter. ${ }^{27}$

Although PMMA/Ag nanocomposites have been synthesized and investigated by several researchers via free radical thermal polymerization ${ }^{28}$ and photopolymerization, ${ }^{5}$ to the best of our knowledge, no empirical research exists addressing the investigation of AgNP effect on PMMA network properties prepared via living radical photopolymerization, i.e., PMP.

In the following, we first describe the synthesis of the AgNPs, then the preparation of PMMA/Ag nanocomposite network via in situ PMP using TED as photoiniferter. The preparation of AgNPs is proven by ultraviolet-visible spectrophotometry (UV-Vis). The effect of AgNPs content on the degree of monomer conversion (DC) and glass transition temperature $\left(T_{\mathrm{g}}\right)$ are investigated using Fourier transform infrared spectroscopy (FT-IR) and differential scanning calorimetry (DSC), respectively. Also, the effect of AgNPs content on swelling behaviour, flexural strength and thermal stability of prepared nanocomposite networks are explained based on gravimetrical method, thermogravimetry analysis (TGA) and three-point flexural test, respectively. Finally, the surfaces of the fractured samples are investigated by field emission scanning electron microscopy (FE-SEM).

\section{Experimental}

\subsection{Materials}

Silver nitrate $\left(\mathrm{AgNO}_{3}\right)$ was purchased from Van Waters Rogers. Methyl methacrylate (MMA), allyl methacrylate (AMA) as crosslinking agent, dried tetrahydrofuran (THF, max. $0.005 \% \mathrm{H}_{2} \mathrm{O}$ ), sodium hydride $(\mathrm{NaH}, 60 \%$ suspension in paraffin oil) as reducing agent, $n$-hexane, tert-butylalcohol $(t-\mathrm{BuOH})$ were purchased from Merck. 2,2-Dimethoxy-2phenylacetophenone (DMPA) as photoinitiator and TED as photoiniferter were obtained from Acros and Merck, respectively. $n$-Hexane and $t$ - $\mathrm{BuOH}$ were distillated from fresh sodium wire before use. Sodium hydride was degreased by twice washing with $n$-hexane and then once with THF. Other materials have been used without any purification.

\subsection{Synthesis of $t$-BuONa-capped AgNP}

Dispersions of nano-sized silver particles were synthesized by reduction of concentrated solutions of $\mathrm{AgNO}_{3}(0.4 \mathrm{M})$ with $t$-BuONa-activated sodium hydride in THF. In this system, sodium tert-butoxide served as a stabilizer, protecting AgNPs from aggregation. To synthesis, a Schlenk tube was loaded with $30 \mathrm{mmol}$ of degreased $\mathrm{NaH}$ and $25 \mathrm{ml}$ THF and the mixture was heated to $65^{\circ} \mathrm{C}$ in nitrogen atmosphere. ${ }^{5} \mathrm{~A}$ solution of $20 \mathrm{mmol} t-\mathrm{BuOH}$ in $5 \mathrm{ml}$ THF was then injected into the tube and the mixture was held at $65^{\circ} \mathrm{C}$ for $5 \mathrm{~min}$. After cooling to room temperature, $10 \mathrm{mmol} \mathrm{AgNO}_{3}$ was added in one portion, within seconds, the clear solution darkens to yellowish. The Schlenk contents were further stirred for another $30 \mathrm{~min} .{ }^{5}$ In final, we had a colloid of $t$-BuONastabilized $\operatorname{Ag}(0)$ nanoparticle in THF, which was stable over months.

\subsection{Synthesis of the Ag/PMMA nanocomposites}

First, solution with concentrations of 5 wt.\% AMA in MMA was prepared and then $1 \mathrm{wt} . \%$ photoinitiators $(0.5 \mathrm{wt} . \%$ DMPA, 0.5 wt.\% TED) was added to the solution and the mixture was stirred to complete dissolution of initiators. Then the appropriate amount of AgNPs was added to the mixture for preparation of $0,0.1,0.3,0.5$ wt.\% dispersion of AgNP in MMA. The mixture was then stirred for 30 min using a magnetic stirrer at ambient temperature. Next, the obtained dispersion was injected into the glass sandwich cell with $1 \mathrm{~mm}$ silicon rubber spacer and samples were irradiated from an ultraviolet light source $(400 \mathrm{w}, \mathrm{Hg}$ vapor, Russia) for $2 \mathrm{~h}$. The thickness of synthesized films was averagely about $1 \mathrm{~mm}$. The final specimens containing $0,0.1,0.3$ and 0.5 wt. $\%$ of AgNP were termed X-sample- 0 , X-sample$0.1, \mathrm{X}$-sample- 0.3 and X-sample- 0.5 , respectively. For comparison, a PMMA nanocomposite containing $0.5 \mathrm{wt} . \%$ of AgNP was prepared via the above procedure in the absence of crosslinker and was termed L-sample-0.5.

\subsection{Nanocomposite network characterization}

2.4a Ultraviolet-Visible spectrophotometry: The formation of AgNPs was confirmed via measurement of surface plasmon band using UV-Vis spectrophotometer (PerkinElmer-Lambada2) from 350 to $800 \mathrm{~nm}, 2$ and 30 min after the beginning of the nanoparticle's synthesis reaction.

2.4b Differential scanning calorimetry: $T_{\mathrm{g}}$ measurements were performed using a DSC-Q100 under $\mathrm{N}_{2}$ flow of $20 \mathrm{ml}$ $\mathrm{min}^{-1}$ and the heating rate of $10^{\circ} \mathrm{C} \mathrm{min}{ }^{-1}$ from 25 to $600^{\circ} \mathrm{C}$.

2.4c Fourier transform infrared spectroscopy: The degree of conversion (DC) of the acrylate monomers was obtained by FT-IR spectroscopy (Bruker-EQUINOX 55) measurements. To fair comparison, the FT-IR spectrums of the nanocomposites before and after polymerization were obtained. To calculate the DC, intensities of the peaks that are responsible for stretching vibrations of $\mathrm{C}=\mathrm{C}\left(1637 \mathrm{~cm}^{-1}\right)$ and $\mathrm{C}=\mathrm{O}\left(1720 \mathrm{~cm}^{-1}\right)$ groups were compared before and after polymerization. The DC of the analysed systems was determined by the following equation:

$$
\text { DC }(\%)=100 \times\left(1-\frac{A_{\text {polymer }}}{A_{\text {monomer }}}\right),
$$

where $A$ is the intensity of $\mathrm{C}=\mathrm{C}$ absorption band divided by the intensity of $\mathrm{C}=\mathrm{O}$ absorption band. ${ }^{29}$ 
2.4d Swelling tests: Swelling tests were measured using the prepared rectangular samples. The samples were immersed in water and ethanol/water $(1 / 3, \mathrm{v} / \mathrm{v})$ at $37 \pm 1^{\circ} \mathrm{C}$ for 30 days. The weight increase percentage (WI\%) in specimens was calculated using the following formula:

$$
\text { Weight increase }(\%)=100 \times\left(\frac{m_{\mathrm{s}}-m_{\mathrm{i}}}{m_{\mathrm{i}}}\right),
$$

where $m_{\mathrm{s}}$ represents the weight of the saturated specimen after 30 days of immersion and $m_{\mathrm{i}}$ represents weight of the unsaturated specimen at first (before immersion).

This is an apparent value for the absorbed solvent, because unreacted monomer is simultaneously extracted resulting in a decrease of specimen weight. For the determination of monomer extracted, the samples were transferred to a vacuum oven maintained at $37^{\circ} \mathrm{C}$ and a similar process to that of sorption repeated during desorption.

The percentage amount of solvent desorbed from specimens, water desorption (WD) or ethanol/water desorption (EWD) was calculated using the following formula:

$$
\text { Solvent desorption }(\%)=100 \times\left(\frac{m_{\mathrm{s}}-m_{\mathrm{d}}}{m_{\mathrm{s}}}\right),
$$

in which $m_{\mathrm{d}}$ represents the weight of the specimen after 30 days desorption. The amount of unreacted monomer extracted by water or ethanolic solution (75\%), during immersion for 30 days, known as 'solubility' (SL) of the composite in these solvents was calculated from the equation:

$$
\text { Solubility }(\%)=100 \times\left(\frac{m_{\mathrm{i}}-m_{\mathrm{d}}}{m_{\mathrm{i}}}\right) \text {. }
$$

The amount of absorbed water (WS) or absorbed ethanol/ water (EWS) as solvent are then given by this formula:

$$
\text { Solvent absorbed }(\%)=\mathrm{WI}+\mathrm{SL} \text {. }
$$

2.4e Flexural strength: Flexural strength of samples were determined on Instron universal testing machine (STM-20 Santam Machine Controller, Iran). A crosshead speed of $0.5 \mathrm{~mm} \mathrm{~min}^{-1}$ was used for flexural strength. The specimens were placed on jigs (supporter) that were $12 \mathrm{~mm}$ apart and then loaded at the centre until fracture occurred. Width of each specimen was measured with a micrometre. For a bar subjected to three-point flexure, flexural strength and flexural modulus in $\mathrm{MPa}$ were calculated from the following equations: ${ }^{36}$

$$
\begin{aligned}
& \text { Flexural strength } \sigma=\frac{3}{2} \frac{F L}{w h^{2}}, \\
& \text { Flexural modulus } E=\frac{F L^{3}}{4 w h^{3} d},
\end{aligned}
$$

where $F(\mathrm{~N})$ is the maximum load applied, $L(\mathrm{~mm})$ is the span between two supports, $w(\mathrm{~mm})$ and $h(\mathrm{~mm})$ are width and thickness of the specimen, respectively, and $d(\mathrm{~mm})$ is the deflection. Each experiment was performed triplicate. 2.4f Field emission scanning electron microscopy: To investigate the fractured surface morphology, the fractured specimen from the flexural test was vacuum-coated with gold and then the digital images were acquired with the FE-SEM (Hitachi S-4160, Japan) at $20 \mathrm{kV}$.

$2.4 \mathrm{~g}$ Thermogravimetric analysis: Thermal stability of nanocomposites was examined using a thermogravimetry analysis (TGA Q50 V6.3 Build) under $\mathrm{N}_{2}$ flow of $20 \mathrm{ml} \mathrm{min}^{-1}$

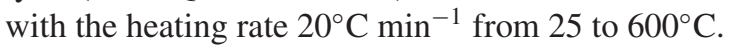

\section{Results and discussion}

The appearance of the plasmon absorption in the UV-Vis spectrum of AgNPs in THF reflects the nano-sized character of the colloidal dispersion of $\operatorname{Ag}(0)$ particles (figure 1).

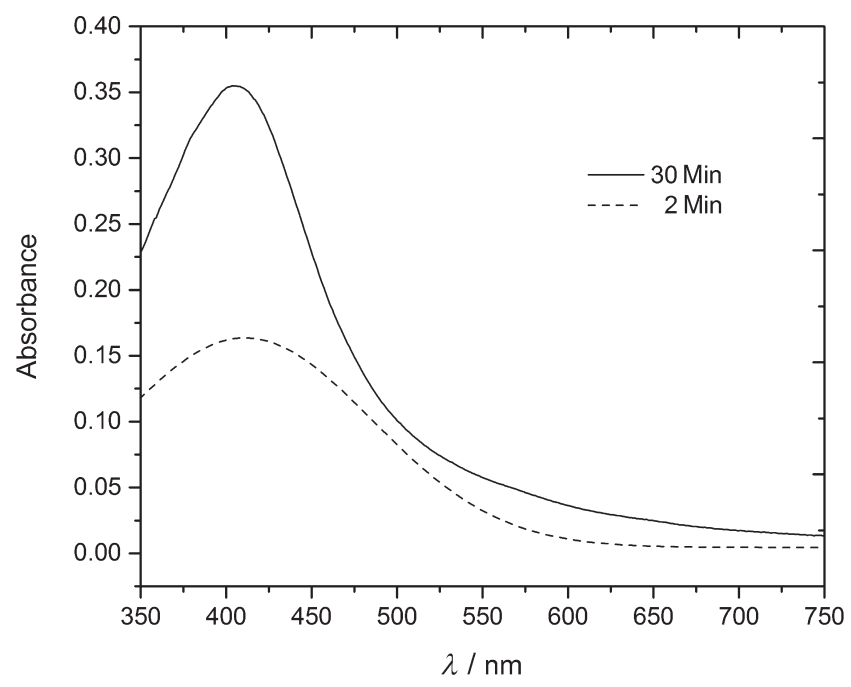

Figure 1. UV-Vis spectra of the AgNPs in THF.

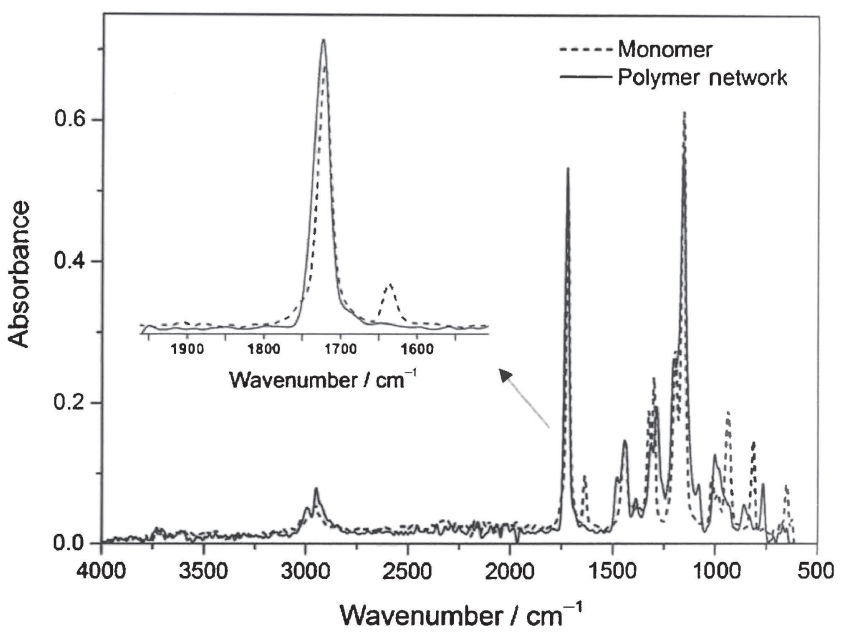

Figure 2. FT-IR spectra of the methyl methacrylate monomer with AgNP and PMMA network AgNP (both samples have 0.5 wt.\% AgNP). 
This represents that $\mathrm{Ag}^{+}$ions are reduced to $\mathrm{Ag}(0)$ in THF. The absorption band is caused by $4 \mathrm{~d} \rightarrow 5 \mathrm{~s}$, p interband transitions. ${ }^{30}$ Balan et $a l^{5}$ investigated the shape, size and size distribution of the synthesized AgNPs via the similar method by transmission electron microscopy (TEM). Their $t$ BuONa-stabilized $\mathrm{Ag}(0)$ nanoparticles were found as spherical particles with a mean diameter (ca. 100 particles counted) of $6.6 \pm 0.3 \mathrm{~nm} .^{5}$ As we precisely followed Balan et al procedure to synthesize AgNPs, it can be expected that the shape and size of the synthesized AgNPs in this study to be comparable to those of synthesized in the study by Balan et al. ${ }^{5}$

Figure 2 shows the FT-IR spectra of MMA with AgNP and the prepared MMA network, X-sample-0.5 included $0.5 \mathrm{wt} \%$ AgNP. The characteristic peak occurred at $1720 \mathrm{~cm}^{-1}$ in

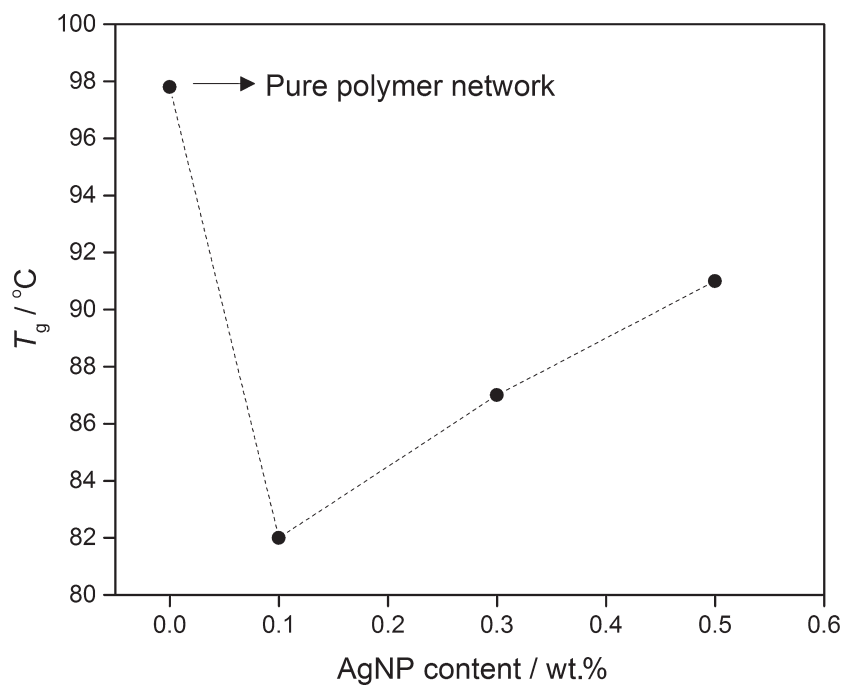

Figure 3. $T_{\mathrm{g}}$ of the neat polymer network and nanocomposite networks. both spectra is attributed to $\mathrm{C}=\mathrm{O}$ stretching in monomer and nanocomposite network. The absorption band at $1640 \mathrm{~cm}^{-1}$ in MMA spectra is characteristics of the $\mathrm{C}=\mathrm{C}$ stretching bond in monomer, and the disappearing of this peak in network spectra confirms the consumption of vinyl bond to form polymer (figure 2). Using FT-IR peak intensity measurements, the monomer conversion (DC) for all samples was calculated from Eq. (1). The DC for X-sample-0, X-sample$0.1, \mathrm{X}$-sample-0.3 and X-sample-0.5 were $92 \pm 1,93 \pm 1$, $95 \pm 1$ and $96 \pm 1 \%$, respectively. These values show a slight increase with increase in the AgNP content. This observation was similar to those reported by Balan et al, ${ }^{5}$ for poly(tetrahydrofurfuryl acrylate)/AgNP nanocomposite network cured by UV. ${ }^{5}$ They also confirmed the catalytic effect of AgNP on DC. ${ }^{5}$ But this catalytic effect of AgNP on DC in Balan's research is more than ours, compare $\sim 8 \%$ changes with $4 \%$ changes in DC in our study in increasing of AgNP from 0 to 0.5 wt. $\%$. This difference may be due to more effective living radical polymerization agents utilized in this study.

A simple way to monitor the effect of AgNP on chain mobility is the investigation of the glass transition behaviour. The glass transition temperature $\left(T_{\mathrm{g}}\right)$ of the neat polymer network is higher than all the nanocomposite networks (figure 3). This reduction in $T_{\mathrm{g}}$ arises from this fact that, due to the presence of capping agent $(t-\mathrm{BuONa})$ around AgNPs, there is no strong polymer-filler interactions in the nanocomposite networks. Therefore, this causes an increase in free volume in the nanocomposite networks due to loosened molecular packing of the polymeric chains near the nanoparticles, one can speak of the plasticization effect. ${ }^{31}$ As well, figure 3 shows an increase in $T_{\mathrm{g}}$ values with increase in AgNP content. Maybe this is related to weak polymer-filler interfacial interactions, i.e., between $\mathrm{AgNP}$ and $\mathrm{C}=\mathrm{O}$ groups of acrylic resin. Consequently, segmental dynamics of chains were restricted in high AgNP content, specifically the

Table 1. Swelling tests for samples in water and ethanolic solution.

\begin{tabular}{|c|c|c|c|c|c|c|}
\hline Sample & $\begin{array}{c}\text { Crosslinking } \\
\text { content (wt.\%) }\end{array}$ & $\begin{array}{c}\text { AgNP content } \\
\text { (wt. } \%)\end{array}$ & WI (\%) & WD (\%) & SL (\%) & WS $(\%)$ \\
\hline \multicolumn{7}{|l|}{ Water } \\
\hline L-Sample-0.5 & 0 & 0.5 & 2.91 & 2.75 & 0.42 & 3.33 \\
\hline X-Sample-0 & 5 & 0 & 0.36 & 0.55 & 0.11 & 0.47 \\
\hline X-Sample-0.1 & 5 & 0.1 & 0.85 & 0.79 & 0.12 & 0.97 \\
\hline X-Sample-0.3 & 5 & 0.3 & 1.05 & 0.96 & 0.15 & 1.21 \\
\hline X-Sample-0.5 & 5 & 0.5 & 1.05 & 1.09 & 0.16 & 1.21 \\
\hline$\underline{\text { Sample }}$ & $\begin{array}{c}\text { Crosslinking } \\
\text { content (wt.\%) }\end{array}$ & $\begin{array}{c}\text { AgNP content } \\
\text { (wt. } \%)\end{array}$ & $\mathrm{WI}(\%)$ & $\operatorname{EWD}(\%)$ & SL $(\%)$ & EWS $(\%)$ \\
\hline \multicolumn{7}{|c|}{ Ethanol/water 3/1 } \\
\hline L-Sample-0.5 & 0 & 0.5 & 35.6 & 35.30 & 1.99 & 37.59 \\
\hline X-Sample-0 & 5 & 0 & 6.07 & 8.13 & 1.09 & 9.26 \\
\hline X-Sample-0.1 & 5 & 0.1 & 9.74 & 9.49 & 1.10 & 10.85 \\
\hline X-Sample-0.3 & 5 & 0.3 & 10.65 & 9.75 & 1.17 & 11.12 \\
\hline X-Sample-0.5 & 5 & 0.5 & 12.24 & 10.19 & 1.27 & 11.51 \\
\hline
\end{tabular}

WI: weight increase, WD: water desorption, SL: solubility, WS: water absorbed, EWD: ethanol/water desorption, EWS: ethanol/water absorbed. 
intensity of interfacial interactions becomes more considerable with increase in AgNP. ${ }^{31}$

The swelling behaviour represented by weight increase (WI), solvent desorption (SD), solubility (SL), water absorbed (WS) and ethanol/water (3/1, v/v) absorbed (EWS) at $37 \pm 1{ }^{\circ} \mathrm{C}$ was calculated from Eqs (2)-(5) and are shown in table 1. The WI results showed an increase with AgNP content in the nanocomposite networks, suggesting the potential catalytic role of the silver nanoparticles in photocrosslinking reactions, which leads to a complete polymer network. This may be due to the interaction between AgNPs and solvents or probably higher heterogeneity of composites in comparison with the unfilled polymer.

All samples showed higher swelling property values for ethanolic solution in comparison with water (table 1). This behaviour can be related to the different chemical affinity

Table 2. Flexural strength and flexural modulus of prepared samples.

\begin{tabular}{lcccc}
\hline & $\begin{array}{c}\text { Crosslinking } \\
\text { content } \\
\text { (wt.\%) }\end{array}$ & $\begin{array}{c}\text { AgNP } \\
\text { content } \\
\text { (wt.\%) }\end{array}$ & $\begin{array}{c}\text { Flexural } \\
\text { modulus } \\
\text { (MPa) }\end{array}$ & $\begin{array}{c}\text { Flexural } \\
\text { strength } \\
\text { (MPa) }\end{array}$ \\
\hline L-Sample-0.1 & 0 & 0.1 & 1034 & 66.1 \\
X-Sample-0 & 5 & 0 & 1034 & 77.9 \\
X-Sample-0.1 & 5 & 0.1 & 1174 & 78.7 \\
X-Sample-0.3 & 5 & 0.3 & 1311 & 82.8 \\
X-Sample-0.5 & 5 & 0.5 & 1620 & 88.4 \\
\hline
\end{tabular}

between the absorbed liquid and the polymer matrix..$^{32,33}$ This reveals that the solubility parameter of resin is closer to ethanol solubility parameter compared to water. Solubility parameters of water, ethanol and MMA are 23.4, 12.7 and $9.5\left(\mathrm{cal} \mathrm{cm}^{-3}\right)^{1 / 2}$, respectively. ${ }^{34,35}$

Table 2 summarizes the results of the determined flexural strength and flexural modulus for all nanocomposite networks. Flexural strength and modulus were increased with increase in AgNPs content. Obviously, this occurred due to very high surface area of the AgNPs in the nanocomposite networks. As a result of high surface area of AgNPs, the applied stress is expected to be easily transformed from the matrix onto the AgNPs, resulting in an enhancement in mechanical properties. In addition, interactions between $\mathrm{C}=\mathrm{O}$ groups of the PMMA chains and AgNPs (weak interactions), which can improve the compatibility between the polymeric matrix and the nanoparticles, result in an increase in mechanical strength. Accordingly, with increase in AgNP content, high volume of chemical interaction leads to an enhancement in flexural strength and modulus. ${ }^{36}$

FE-SEM micrographs from the fractured surface of the samples, resulted from the three-point flexural test, indicated a good agreement between surface morphology and the results of the flexural test. The neat polymer network showed a smooth surface morphology (figure 4a). For the nanocomposite networks, however, the FE-SEM micrographs revealed a rough surface morphology (figure $4 b-d$ ). Qualitatively speaking, the scale of fractured surface roughness increases with increase in AgNP content (figure 4b-d). This can be
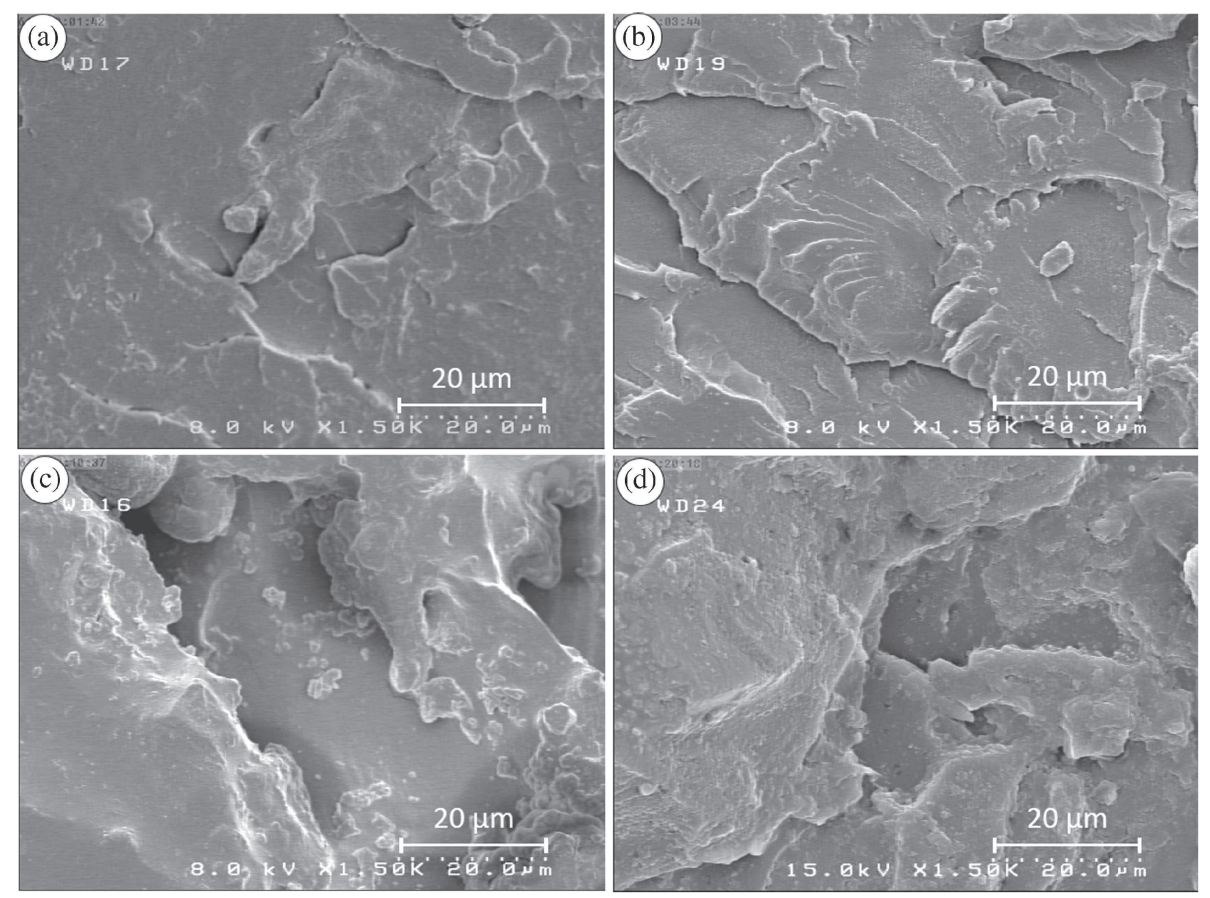

Figure 4. FE-SEM micrographs of the fractured surface of the nanocomposite networks resulted from the three-point flexural test. (a) X-sample-0 (neat polymer network), (b) Xsample-0.1 (with 0.1 wt.\% AgNP), (c) X-sample-0.3 (with 0.3 wt. $\%$ AgNP) and (d) X-sample0.5 (with 0.5 wt.\% AgNP). 

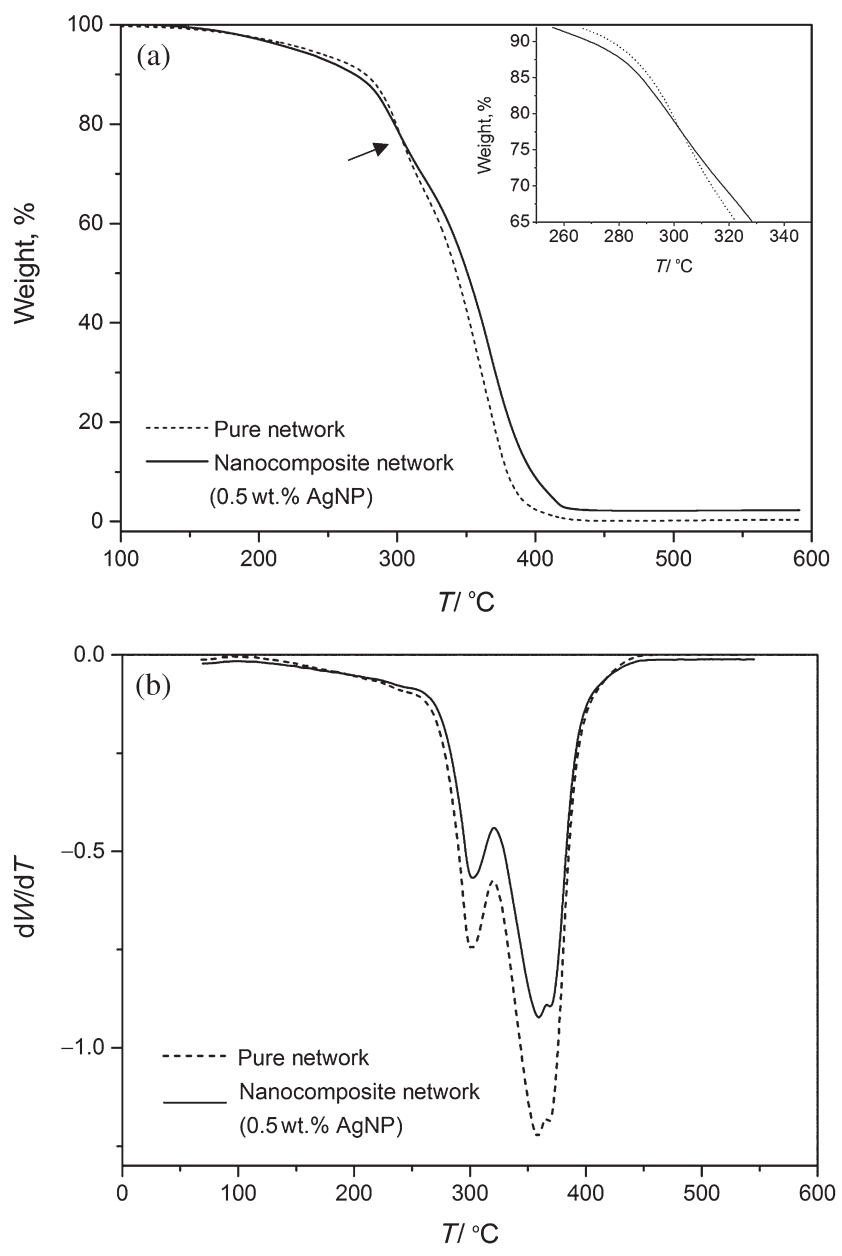

Figure 5. (a) TGA and (b) DTG of pure polymer network and nanocomposite network (X-sample-0.5 with $0.5 \% \mathrm{AgNP}$ ).

attributed to the act of AgNPs as toughening agent confirmed by enhanced flexural modulus and strength.

The TGA and differential thermogravimetric analysis (DTG) disclosed that the presence of AgNPs in the polymer network had a conflicting effect on thermal properties (figure 5). In the early stages of thermal degradation process, AgNPs promoted degradation rate of polymer network and then caused to thermal stability against degradation in higher temperatures. In fact, AgNPs acted as degradation catalyst in early stages (around $320-420^{\circ} \mathrm{C}$ ), in which the temperature at maximum degradation, known as peak temperature, shifted to lower temperatures. But, in subsequent stages (around $350-370^{\circ} \mathrm{C}$ ), AgNPs acted as a degradation retardant, namely the peak temperature shifted to higher temperatures.

\section{Conclusion}

In this study, PMMA nanocomposite networks that included various amount of AgNP were synthesized by in situ PMP approach. The calculated degree of monomer conversion (DC\%) for all prepared nanocomposite networks was slightly increased, varied from $92 \pm 1$ to $96 \pm 1 \%$, with an increase in AgNP content from 0 to $0.5 \mathrm{wt} . \%$, which suggested catalytic effect of AgNP on photo-crosslinking reactions. Swelling behaviour of the samples measured in water and ethanolic solution $(75 \%, v / v)$ showed an increase in swelling ratio with increase in AgNP content. Moreover, in comparison with the neat polymer network, the mechanical properties of nanocomposites showed higher values of flexural strength and modulus. FE-SEM images revealed a rough fracture surface for the nanocomposite networks vs. smoother surface for the neat polymer network, suggesting the role of AgNPs as toughening agent. Thermal stability investigations unfolded the catalytic effect of AgNPs in the early stages and their retarding effect on thermal degradation of the polymer networks in the subsequent stages. These findings have the potential to contribute to the novel paradigms for the fabrication of well-defined antimicrobial materials for dental applications.

\section{Acknowledgement}

Partial financial support from the Iranian Nanotechnology Initiative and the vice-president for Research and Technology of University of Tehran is gratefully appreciated.

\section{References}

1. Ladha K and Shah D 2011 J. Indian. Prosthodont. Soc. 11215

2. Peyton F A 1975 Dent. Clin. N. Am. 19211

3. Whitters C J, Strang R, Brown D, Clarke R L, Curtis R V, Hatton A J et al 1999 J. Dent. 27401

4. Ivar A M, Moorhead J E and Dahl J E 1999 Acta. Odontol. Scan. $\mathbf{5 7} 257$

5. Balan L, Schneider R and Lougnot D J 2008 Prog. Org. Coat. 62351

6. Balan L, Malval J P, Schneider R and Burget D 2007 Mater. Chem. Phys. 104417

7. Stafford G D and Smith D C 1970 Brit. Dent. J. 128442

8. Smith D C 1962 J. Prosthet. Dent. 121066

9. Meerburg F, Hennebel T, Vanhaecke L, Verstraete W and Boon Nico 2012 Microb. Biotechnol. 5388

10. Grinou A, Bak H, Yun Y S and Jin H J 2012 J. Disper. Sci. Technol. $\mathbf{3 3} 750$

11. Kassaee M Z, Akhavan A, Sheikh N and Sodagar A 2008 J. Appl. Poly. Sci. 1101699

12. Jiang H, Manolache S, Lee Wong A C and Denes F S 2014 J. Appl. Poly. Sci. 931411

13. Afanasev D S, Yakovina O A, Kuznetsova A S and Listsyn A S 2012 Catal. Commun. 2243

14. Alt V, Bechert T, Steinrucke P, Wagener M, Seidel P, Dingeldein E et al 2004 Biomaterials 254383

15. She W J 2004 Dent. Mater. 27176

16. Radetić M, Ilic V, Vodnik V, Dimitrijevic S, Jovancic P, Saponic Z et al 2008 Polym. Advan. Technol. 191816

17. Vimala K, Murali Mohan Y, Samba Sivudu K, Varaprasad K, Ravindra S, Narayana Reddy N et al 2010 Colloid. Surf. B 76 248 
18. Silver S and Phung L T 1996 Annu. Rev. Microbiol. 50753

19. Chattopadhyay D, Pandra S S and Raju K V S N 2005 Prog. Org. Coat. 5410

20. Moszner N and Salz U 2001 Prog. Poly. Sci. 26535

21. Harris B P and Metters A T 2006 Macromolecules 392764

22. Rahane S B, Kelbey S M and Metters A T 2005 Macromolecules $\mathbf{3 8} 8202$

23. Rahane S B, Metters A T and Kilbey S M 2006 Macromolecules 398987

24. Rahane S B, Kilbey S M and Metters A T 2008 Macromolecules 419612

25. Rahane S B, Floyd J A, Metters A T and Kilbey S M 2008 Adv. Funct. Mater. 181232

26. Rahane S B, Metters A T and Kilbey S M 2010 J. Polym. Sci. A Polym. Chem. 481586
27. Li A, Benetti E M, Tranchida D T, Clasohm J N, Schonherr H and Spencer N D 2011 Macromolecules 445344

28. De Boer B, Simon H K, Werts M P L, Van der Vegte E W and Hadziioannou G 2000 Macromolecules 33349

29. Podgórski M 2010 Dent. Mater. 26188

30. Meisel D 1998 J. Phys. Chem. B 1028364

31. Pandis Ch, Logakis E, Kyritsis A, Pissis P, Vodnik V V, Dzunuzovic E et al 2011 Eur. Poly. J. 471514

32. Wu W and McKinney J E 1982 J. Dent. Res. 611180

33. Kao E C 1989 Dent. Mater. 5201

34. Hughes L J and Britt G E 1961 J. Appl. Poly. Sci. 5337

35. Hiorns R 1991 Polymer handbook 4th ed (New York: John Wiley and Sons) p 2250

36. Sodagar A, Kassaee M Z, Akhavan A, Javadi N, Arab S and Kharazifard M J 2011 J. Prosthodont. Res. 56120 